\title{
Preface by the organizers
}

The papers collected in this online volume were presented at the $24^{\text {th }}$ Conference on Semantics and Linguistic Theory, North America's foremost conference devoted to natural language semantics with relevance to linguistic theory. SALT 24 was hosted at New York University from May $30^{\text {th }}$ to June $1^{\text {st }}, 2014$.

The four invited speakers were Emmanuel Chemla (ENS), Valentine Hacquard (Maryland), Lauri Karttunen (Stanford), and Sarah Moss (Michigan).

The conference featured 14 talks and 24 posters. They were selected from 246 submissions, based on 955 reviews by 187 reviewer colleagues, by the program committee, consisting of Chris Barker, Lucas Champollion, Simon Charlow, Salvador Mascarenhas, Philippe Schlenker, and Anna Szabolcsi.

Not all presenters have submitted papers to this volume. For the full program, with abstracts, slides, handouts, and posters for download, see nyu.edu/salt2014.

115 people registered for the conference, and audiences over the three days held steady at just under 100 . We gratefully thank our graduate students, department chairs Chris Barker and Alec Marantz, and Deans Michael Laver and Thomas J. Carew for their help, which made this conference possible.

The lead editor for this volume is Todd Snider, and his fellow editors at the Cornell Linguistics Circle are Sarah D'Antonio and Mia Wiegand.

Starting with this year, the SALT proceedings are no longer using eLanguage to host them and are moving to a differently branded server based on Open Journal Systems. As was the case for previous proceedings, this volume is released online for free. Both platforms are hosted by the Linguistic Society of America, whose support we gratefully acknowledge.

Lucas Champollion and Anna Szabolcsi

for the organizing team 